\title{
BIBLIOTECAS DE MARIA BONOMI
}

Gustavo Piqueira

Um espaço construído para armazenar um único tipo de artefato deveria ser algo simples e sem muito charme. Sua dimensão variaria em função da quantidade de objetos ali depositados, sua organização atenderia a um ou outro critério de classificação e pronto. Um espaço construído para armazenar um único tipo de artefato deveria ser algo simples e sem muito charme, não fosse esse artefato aquele que, alheio às revoluções tecnológicas que de tempos em tempos anunciam seu fim, segue perpassando os séculos a ostentar o status de símbolo máximo do homem enquanto ser cultural. Desse modo, os tais depósitos cumprem suas tarefas utilitárias e, oficialmente, até as exibem como funções primordiais. Na verdade, porém, muitas vezes as relegam a um segundo plano e mal conseguem disfarçar que uma biblioteca se projeta para muito além da função manifesta pela qual foi erguida.

Não à toa, enquanto alguns de seus acervos tiveram origem em coleções cujo fim se restringia aos livros em si, o mesmo não se pode dizer dos edifícios construídos para abrigá-los. Assim, os textos escritos por Marisa Midori, breves descrições de vinte e três bibliotecas 


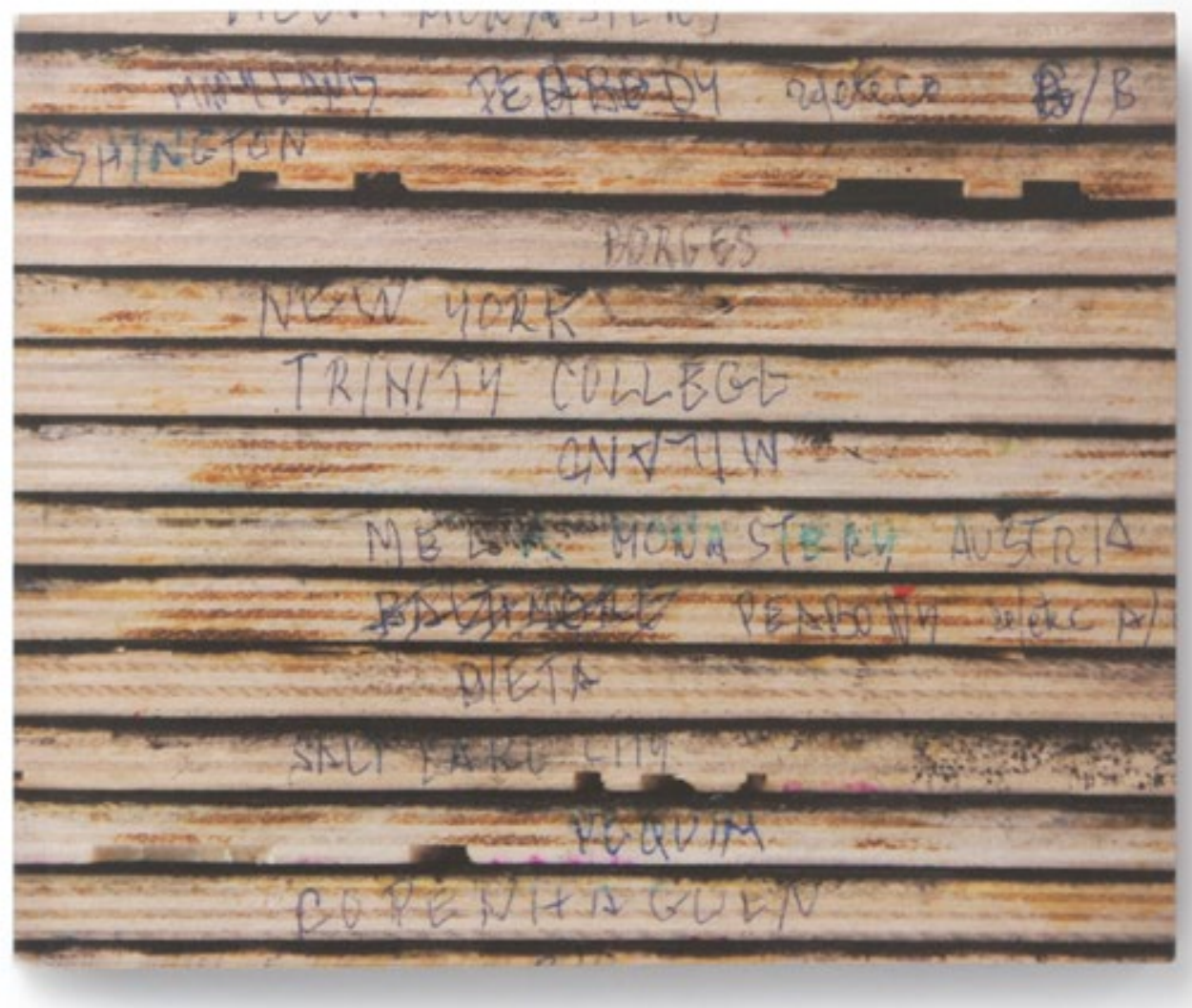

\author{
As Bibliotecas de Maria \\ Bonomi. Marisa Midori Deaecto. \\ São Paulo, Publicações BвM, 2017. \\ ISBN 978-85-6258-725-2, $25 \times 20 \mathrm{~cm}$
}


cronologicamente dispostas em As Bibliotecas de Maria Bonomi ${ }^{1}$, não relatam apenas a evolução das tecnologias de preservação dos livros, nem se restringem à transformação do espaço de uma biblioteca como reflexo de mudanças nos hábitos de leitura ou na direção dos ventos arquitetônicos: via de regra as histórias narradas falam mais de quem promoveu sua construção do que dos edifícios propriamente ditos. Afinal, como todo palácio que se preze, as bibliotecas materializam as imagens que seus patronos desejam imortalizar de si mesmos. Ainda sobre isso, a autora pontua na introdução da obra:

Na ausência de uma imagem que tenha fixado o modelo daquele antigo templo dos livros que o homem destruiu, mas que não se apagou da memória das civilizações, toda biblioteca se converteria, por extensão, em uma releitura do museu alexandrino.

Essa ausência de tangibilidade da referência de onde partiram - e partem - todas as bibliotecas, no entanto, nunca se configurou como um problema. Pelo contrário: revivia-se o mito da Biblioteca de Alexandria, mas revestido de um semblante próprio, apropriando-se de sua dimensão simbólica e moldando-a livremente para que ela pudesse narrar outras histórias.

Nada contra. É para isso, aliás, que seguimos escrevendo e imprimindo livros: para contarmos outras histórias. Cada tempo, cada homem, deve grafar as suas. É, aliás, o que faz Maria Bonomi neste livro. Vinte e três vezes, para ser mais exato.

Pois, ainda que se constituam num conjunto de inegável coesão, cada uma das xilogravuras opta por iluminar atributos específicos de seu respectivo modelo. Mais do que descrever visualmente edifício a edifício, Maria Bonomi pinça particularidades formais únicas de cada espaço e as utiliza como ponto de partida para a execução de suas xilogravuras. Assim, a Biblioteca Ambrosiana e a Joanina surgem em vistas centrais na altura do espectador, mas, enquanto a primeira abre o plano para incorporar a eloquência de seu teto, a última se concentra no contraste entre a teatralidade do barroco joanino da portada e a rígida ortogonalidade das prateleiras de livros. A biblioteca do British Museum aparece num recorte que realça sua ossada curvilínea, a Seattle Central Library exibe a fachada assimétrica desenhada por Rem Koolhas e assim por diante. A variedade e a riqueza da série, portanto, extrapola - e muito - qualquer intenção didática. 

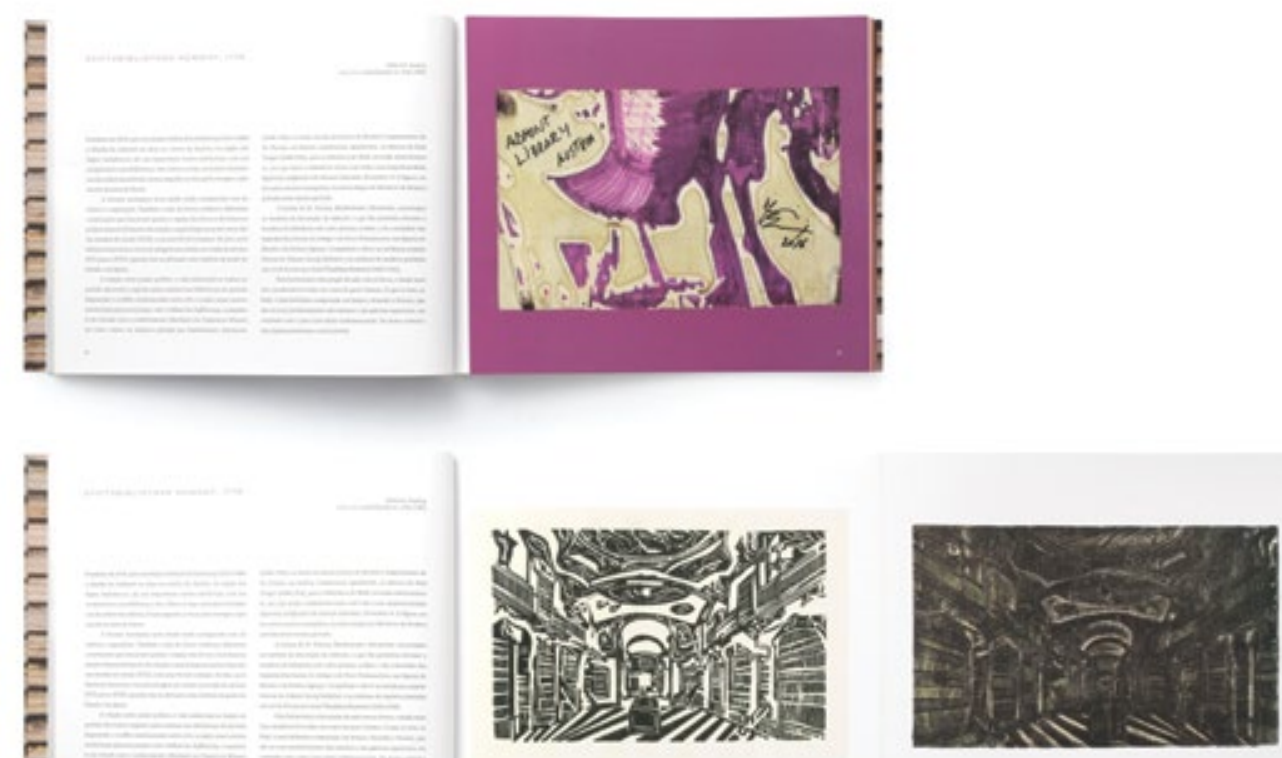

Mas as histórias contadas neste As Bibliotecas de Maria Bonomi não terminam aí: a materialidade do livro também narra a sua. Cada uma das bibliotecas surge em página dupla. Texto à esquerda, imagem à direita. Contudo, se as palavras se apresentam sem nenhum empecilho, do outro lado o leitor se depara com reproduções fotográficas de superfícies de madeira rabiscadas com aparente desleixo, acompanhadas por anotações assistemáticas que nomeiam a respectiva biblioteca - muitas vezes de modo abreviado, como se uma anotação rápida para uso pessoal. É o que de fato são. Basta virarmos a não usual dobra de página para descobrirmos que se tratam de reproduções - frente e verso das matrizes de madeira entalhadas por Maria Bonomi. Assim, o virar da página, ato essencial da leitura, se torna uma lúdica experiência que brinca de repetir o movimento da grande gravurista ao descolar a folha de papel de sua matriz para, com isso, examinar o resultado impresso pelo relevo entintado. Para além do jogo, o recurso também traz à tona não só o processo de criação das gravuras, mas a própria estrutura do livro e, com isso, encerra a ampla jornada que sai das matrizes de impressão em madeira - origem dos primeiros livros impressos no Ocidente, os xylographica pré-Gutenberg, até alcançar as nuvens de hoje. E, após tantas voltas, tantas narrativas paralelas que parecem se desenvolver livremente, não é de se estranhar que os percursos de As Bibliotecas de Maria Bonomi sejam arrematados, no último nome da lista, pela Biblioteca de Jorge Luis Borges. 